\title{
Pattern of Antihypertensive Treatment and Blood Pressure Control among Diabetic Outpatients in Addis Ababa, Ethiopia
}

Hailu A Mulatu*, Tola Bayisa, Tesfaye Berhe and Esubalew Woldeyes

Department of Internal Medicine, St. Paul's Hospital Millennium Medical College, Ethiopia

"Corresponding author: Hailu A Mulatu, Department of Internal Medicine, St. Paul's Hospital Millennium Medical College, Ethiopia, Tel: +2519116782879; E-mail: dhailu2001@gmail.com

Received date: April 15, 2017; Accepted date: April 28, 2017; Published date: April 30, 2017

Copyright: ( 2017 Mulatu HA, et al. This is an open-access article distributed under the terms of the Creative Commons Attribution License, which permits unrestricted use, distribution, and reproduction in any medium, provided the original author and source are credited.

\begin{abstract}
Introduction: Hypertension and diabetes mellitus are currently the usual causes of morbidity and mortality among non-communicable diseases in both developed and developing countries. When occur together, the risk of death from cardiovascular diseases will double.

Objective: This study was intended to assess the antihypertensive drug prescription pattern and blood pressure control among diabetic outpatients at St. Paul's tertiary Hospital in Addis Ababa.

Methods: A hospital based cross- sectional study design was used to review the medical registries of 484 diabetic-hypertensive outpatients seen between February $1^{\text {st }} 2016$ and July 302016.

Results: The most commonly used antihypertensive drug classes in our patients were angiotensin converting enzyme inhibitor in 283 (58.5\%), calcium channel blocker in 218 (45\%) and beta blocker in 61 (12.8\%) patients. The most commonly used monotherapy is angiotensin converting enzyme inhibitor in $110(22.7 \%)$, calcium channel blocker in $89(18.4 \%)$ and diuretic in $25(5.2 \%)$. The currently recommended target systolic blood pressure <140 $\mathrm{mmHg}$ and diastolic blood pressure $<90 \mathrm{mmHg}$ was achieved in $176(36.4 \%)$ patients while the majority $308(63.6 \%)$ did not attain the target blood pressure. Renal function was assessed in $484(100 \%)$ patients, of whom 24 (5\%) had renal impairment with an estimated glomerular filtration rate $<60 \mathrm{ml} / \mathrm{min} / 1.73 \mathrm{~m}^{2}$.
\end{abstract}

Conclusion: The antihypertensive drug treatment pattern in our patients was in agreement with the current treatment guidelines. However, blood pressure control in the majority of patients is not adequate.

Keywords: Blood pressure; Chronic kidney disease; Diabetes mellitus; Hypertension; Treatment guideline

\section{Introduction}

The prevalence of diabetes mellitus (DM) is increasing dramatically over the last two decades being the major cause of mortality accounting for 5.1 million deaths or $8 \%$ of deaths worldwide in 2013 [1]. Based on the International Diabetes Federation (IDF) 2015 report, the global estimate of DM in adult population aged 20-79 years was 441 million, with an African regional prevalence of $3.2 \%$ and an estimate of 0.8-3.5 million people living with diabetes in Ethiopia [2].

Hypertension is also increasing in magnitude and severity, especially in blacks being associated with higher rates of morbidity and mortality [3]. It has been identified as a major risk factor not only for the development of diabetes, but also for coronary artery disease, stroke and kidney disease in patients with diabetes [4].

Macrovascular and microvascular complications associated with diabetes and hypertension can be more effectively reduced with control of blood pressure than blood glucose. Therefore, adequate management of hypertension among patients with diabetes mellitus is cost effective [5].
In Ethiopia, the antihypertensive treatment pattern among diabetichypertensive patients was not widely studied. In a study recently conducted in Addis Ababa on a smaller public hospital the antihypertensive treatment pattern was consistent with the current evidence- based guidelines. But, the blood pressure control level to target was not adequate [6].

The importance of evidence based antihypertensive treatment practice in diabetic patients who are at high risk of vascular complications has been stressed in many guidelines, because the inappropriate use of these drugs has deleterious socioeconomic impact for patients and the country [7]. Therefore, it is rational to assess the antihypertensive drug prescription practice in Ethiopia.

\section{Material and Methods}

The study was conducted at St. Paul's Hospital, the second largest teaching hospital in Addis Ababa, which can represent most of the academic hospitals in Ethiopia.

A hospital based cross-sectional study design was used to review the medical records of all diabetic-hypertensive patients who visited St. Paul's teaching Hospital in the period between February $1^{\text {st }}$ and July $31^{\text {st }} 2016$ 
Page 2 of 4

A total of 484 diabetic- hypertensive patients visited the diabetic clinic during the study period. The medical records of all patients were used to obtain demographic information, diagnostic information, vital signs, laboratory test results and prescribed drugs using a structured questionnaire. The last visit blood pressure and fasting blood glucose measurements were utilized for the study. Glomerular filtration rate (GFR) was calculated using software with Modification of Diet in Renal Disease (MDRD) equation.

All data were entered and analyzed using Statistical Software for Social Sciences (SPSS) version 20.0. Errors related to inconsistency of data were corrected during data clearing. Univariate analysis, such as frequency, percentage, distributions and appropriate graphic presentations besides the measure of central tendency and measure of dispersion were used for describing the data. The independent variables were compared using a chi-square test and considered significant at a p-value of $<0.05$.

Ethical approval was obtained from St. Paul's Hospital Millennium Medical College institutional review board.

\section{Results}

A total of 1200 diabetic patients, of whom 484 (40.3\%) diabetichypertensive patients visited the follow up clinic during the study period. Two hundred forty-one (49.8\%) patients were males and male to female ratio was nearly $1: 1$. The mean age of patients was $57.8 \pm 10.2$ years. The majority of patients lie in the age range of $46-60$ years (55.6\%) followed by $61-75$ years $(28.3 \%)$ (Figure 1 ).

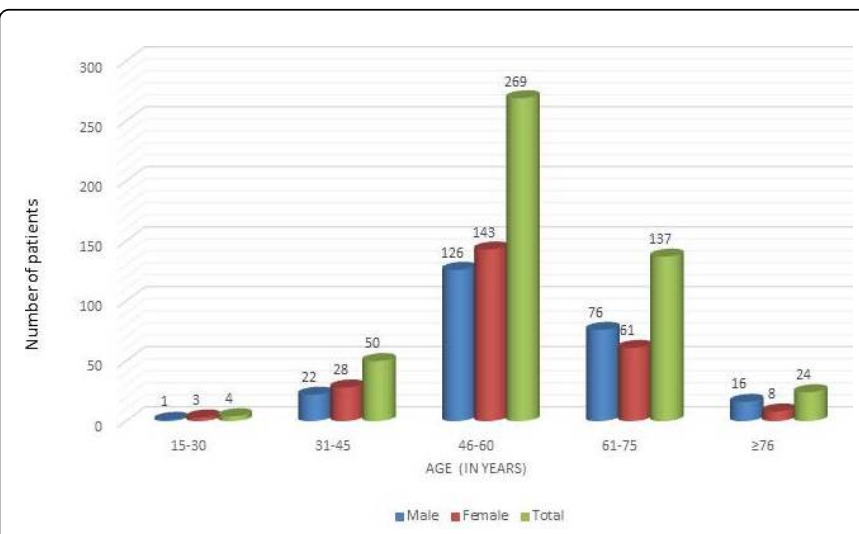

Figure 1: Age distribution of study population $(n=484)$.

The majority (98.1\%) of patients had type 2 diabetes mellitus and the rest $(1.9 \%)$ had type 1 diabetes mellitus. The mean durations of diabetes and hypertension were 9.6 and 8 years respectively. The means of the most recent systolic and diastolic blood pressures were $143.2 \pm$ 16.3 and $17.3 \pm 10.7 \mathrm{~mm} \mathrm{Hg}$ respectively. The currently recommended target $\mathrm{SBP}<140 \mathrm{~mm} \mathrm{Hg}$ and $\mathrm{DBP}<90 \mathrm{~mm} \mathrm{Hg}$ was achieved in 176 (36.4\%) patients while in the rest $308(63.6 \%)$ patients it was beyond the target. The mean fasting blood glucose level during the last visit of the study subjects was $162.1 \pm 55.4 \mathrm{mg} / \mathrm{dl}$. The commonly prescribed anti-diabetic medications were glebenclamide plus metformin in 174 (36\%), insulin in $117(24.2 \%)$ and metformin in 90 (18.6\%) patients. Only twenty-four (5\%) patients had renal impairment with an estimated glomerular filtration rate (GFR) $<60 \mathrm{ml} / \mathrm{min} / 1.73 \mathrm{~m}^{2}$ (Table $1)$.

\begin{tabular}{|c|c|}
\hline Parameter & Value \\
\hline \multicolumn{2}{|l|}{ Address (by region) } \\
\hline Addis Ababa & $363(75 \%)$ \\
\hline Oromia & $111(22.9 \%)$ \\
\hline Amhara & $1(0.2 \%)$ \\
\hline SNNP & $9(1.9 \%)$ \\
\hline \multicolumn{2}{|l|}{ Religion } \\
\hline Orthodox Christian & $315(65.1 \%)$ \\
\hline Muslim & $87(18 \%)$ \\
\hline Protestant & $81(16.7 \%)$ \\
\hline Other & $1(0.2 \%)$ \\
\hline \multicolumn{2}{|l|}{ Type of Diabetes Mellitus } \\
\hline Type 1 & $9(1.9 \%)$ \\
\hline Type 2 & $475(98.1 \%)$ \\
\hline Duration Diabetes Mellitus (mean in years) & $9.6(1-41)$ \\
\hline Fasting Blood Glucose (mean \pm SD in $\mathrm{mg} / \mathrm{dl}$ ) & $162.1 \pm 55.4$ \\
\hline \multicolumn{2}{|l|}{ Type of anti-diabetic treatment } \\
\hline Glebenclamide & $27(5.5 \%)$ \\
\hline Metformin & $90(18.6 \%)$ \\
\hline Glebenclamide and metformin & $174(36 \%)$ \\
\hline Insulin & $117(24.2 \%)$ \\
\hline Insulin and metformin & $76(15.7 \%)$ \\
\hline Duration of Hypertension (mean in years) & $8.0(0.5-41)$ \\
\hline Systolic blood pressure (mean SD in mmHg) & $143.2 \pm 16.3$ \\
\hline Diastolic blood pressure (mean $\pm \mathrm{SD}$ in $\mathrm{mmHg}$ ) & $79.3 \pm 10.7$ \\
\hline \multicolumn{2}{|l|}{ Blood Pressure goal for diabetes mellitus } \\
\hline$<140 \mathrm{mmHg}$ and $<90 \mathrm{mmHg}$ & $176(36.4 \%)$ \\
\hline$\geq 140 \mathrm{mmHg}$ or $\geq 90 \mathrm{mmHg}$ & $308(63.6 \%)$ \\
\hline \multicolumn{2}{|l|}{ Glomerular filtration rate $\left(\mathrm{ml} / \mathrm{min} / 1.73 \mathrm{~m}^{2}\right)$} \\
\hline$\geq 60$ & $460(95 \%)$ \\
\hline$<60$ & $24(5 \%)$ \\
\hline \multicolumn{2}{|l|}{ Clinic attendance in the last 1 year } \\
\hline$\geq 75 \%$ & $481(99.4 \%)$ \\
\hline$<75 \%$ & $3(0.6 \%)$ \\
\hline
\end{tabular}

Table 1: Characteristics of study population $(n=484)$.

The average number of antihypertensive medications prescribed per patient was $1.7 \pm 0.7$ (range 1-4). Monotherapy was prescribed for 235 (48.6\%) and combination anti-hypertensive for 249 (51.4\%) patients. 
Angiotensin converting enzyme inhibitor (ACEI) and calcium channel blocker (CCB) were the most frequently prescribed anti-hypertensive drug classes in $313(64.5 \%)$ and $248(51.2 \%)$ patients respectively (Table 2).

\begin{tabular}{|c|c|c|c|c|c|}
\hline Drug class, n (\%) & $\begin{array}{l}\text { Overall } \\
\mathrm{N}=484(100.0 \%)\end{array}$ & $\begin{array}{l}1 \text { Drug } \\
n=235(48.6 \%)\end{array}$ & $\begin{array}{l}2 \text { Drugs } \\
n=188(38.8 \%)\end{array}$ & $\begin{array}{l}3 \text { Drugs } \\
n=58(12 \%)\end{array}$ & $\begin{array}{l}4 \text { or more Drugs } \\
n=3(0.6 \%)\end{array}$ \\
\hline ACE inhibitors & $313(64.5 \%)$ & $110(46.8 \%)$ & $151(80.3 \%)$ & $49(84.5 \%)$ & $1(33.3 \%)$ \\
\hline Angiotensin II inhibitors & $18(3.7 \%)$ & $8(3.4 \%)$ & $7(3.7 \%)$ & $2(3.4 \%)$ & - \\
\hline Calcium channel blockers & $248(51.2 \%)$ & $89(37.9 \%)$ & $106(56.4 \%)$ & $50(86.2 \%)$ & $1(33.3)$ \\
\hline$\beta$ - blockers & $61(12.6 \%)$ & $1(0.4 \%)$ & $30(16.0 \%)$ & $27(46.6 \%)$ & $1(33.3 \%)$ \\
\hline Thiazide or loop diuretics & $156(32.2 \%)$ & $25(10.6 \%)$ & $82(43.6 \%)$ & $46(79.3 \%)$ & $1(33.3 \%)$ \\
\hline a-blockers & $2(0.4 \%)$ & $2(0.9 \%)$ & - & - & - \\
\hline
\end{tabular}

Table 2: Patterns of use of anti-hypertensive drugs among patients with single- versus multidrug hypertension.

Among fourteen different combination anti-hypertensive regimens used in the study population, the most frequently prescribed combinations were ACEI plus CCB and ACEI plus diuretic (DI) in 74 $(15.3 \%)$ and $60(12.4 \%)$ patients respectively. Patients with renal impairment $\left(\mathrm{GFR}<60 \mathrm{ml} / \mathrm{min} / \mathrm{m}^{2}\right)$ tended to have better blood pressure control as compared to those with no renal impairment, although this was not statistically significant $(p=0.069)$. There were also no significant differences in the overall utilization of antihypertensive drug classes among patients with controlled or uncontrolled blood pressure.

\section{Discussion}

We studied the pattern of antihypertensive treatment and control of blood pressure in diabetic patients in a tertiary teaching hospital, whether they were consistent with the current recommendations. Our study showed that a significant number $(48.6 \%)$ of patients were on a single drug regimen, not reflecting the pattern seen in several previous trials $[6,8]$. The choice of anti-hypertensive drug is governed by the drug's capacity to decrease blood pressure, renal and cardiovascular complications associated with diabetes. Among the widely used antihypertensive drugs, ACEIs have shown a reduction in cardiovascular events compared to diuretics or CCBs $[9,10]$.

The most commonly prescribed drugs in our study were ACEI in $283(58.5 \%)$ followed by CCB in 218 (45\%) patients. They are recommended as first line drugs in many guidelines, including JNC VII [11]. The most frequently prescribed monotherapy and combination therapies were ACEI (22.7\%) and ACEI plus CCB (15.3\%) respectively. These findings were similar to studies from Ethiopia, Saudi Arabia and India [6,12,13]. Unlike studies from many other countries, ARB was utilized only in 17 (3.5\%) patients, mainly due to cost and unavailability of generic forms of the regimen $[6,14]$.

Several large clinical trials and guidelines recommend the use of multiple antihypertensive drugs in order to achieve adequate and sustained blood pressure control $[9,10,15]$. The majority of our treated patients $(51.4 \%)$ were on multi-drug regimens. But, only one- third of our diabetic patients have reached goal blood pressure below 140/90 $\mathrm{mm} \mathrm{Hg}$. Although, the results of this study were similar to the findings of published studies in other countries [16,17], the blood pressure control is better than a similar study conducted in a non-academic hospital in Ethiopia [6]. Despite the presence of clear recommendations about blood pressure goals, the majority of our diabetic patients did not attain adequate control $[18,19]$. This might be due to poor compliance and inadequate dosing titration. Health professionals also fail to educate them about the nature of their illness and the need for adequate blood pressure control. The cost of the drugs is also another challenge. Unlike in developed countries, the majority of our patients is paying out of their pockets for their health expenses. For this reason, they may not afford to buy multiple antihypertensive medications [18-21].

There is an abundance of literature about the benefit of ACEIs and ARBs for additional vascular and reno-protective effects of decreasing disease progression. Therefore, either are recommended to include in the regimen for those with diabetic kidney disease [17,22,23]. In 24 (5\%) of our study subjects, renal impairment with GFR $<60 \mathrm{ml} / \mathrm{min} /$ $1.73 \mathrm{~m}^{2}$ was found. ACEI/ ARB was used in 19 (3.9\%), either as mono or combination therapy. This shows that among patients with renal impairment, the majority (79.2\%) were on ACEI or ARB, which was better than another study in the country, but still lower than studies in other countries $[6,13]$. In the rest $20.8 \%$ of patients with renal disease, ACEI or ARB was not utilized.

\section{Limitations of the Study}

Diabetes patients who visited a public hospital were involved in this study. These may be different from patients in private health facilities. Therefore, the results may not be generalizable to all patients with diabetes and hypertension.

\section{Conclusion and Recommendation}

In this study, the pattern of antihypertensive medications used was in agreement with the current treatment guidelines. But, the blood pressure control in these patients was not adequate.

Therefore, more strict control of blood pressure is needed to reduce severe complications of diabetes and hypertension. 
Citation: Mulatu HA, Bayisa T, Berhe T, Woldeyes E (2017) Pattern of Antihypertensive Treatment and Blood Pressure Control among Diabetic Outpatients in Addis Ababa, Ethiopia. J Diabetes Metab 8: 738. doi:10.4172/2155-6156.1000738

Page 4 of 4

\section{Authors Contributions}

HA conceived and designed the study and oversaw the data collection process. All authors analyzed the data and wrote the final draft and approved it.

\section{Acknowledgements}

We are very grateful to St. Paul's Hospital Millennium Medical College Research Directorate for funding this work.

\section{References}

1. Alvin CP (2015) Harrison's Principles of Internal Medicine (19thend). In Al. L et, editor. Harrison's Principles of Internal Medicine. (19th edn). Pp 2399-2407.

2. International Diabetes Federation (2015) IDF Diabetes Atlas. P 1-527.

3. Anne LT, Jackson TW, ILP (2015) Braunwald's Heart Disease区: A Textbook of Cardiovascular Medicine. (10thedn) Mann DL, Douglas PZ (editors), 24-26 p.

4. De Pablos-Velasco P, Gonzalez-Albarran O, Estopiñan V, Khanbhai A (2007) Blood pressure, antihypertensive treatment and factors associated with good blood pressure control in hypertensive diabetics: The Tarmidas study. J Hum Hypertens 21:664-672.

5. Adler AI, Stratton IM, Neil HA, Yudkin JS, Matthews DR, et al. (2000) Association of systolic blood pressure with macrovascular and microvascular complications of type 2 diabetes (UKPDS 36). BMJ 321: 412-419.

6. Abera H, Woldemichael M (2016) Pattern of antihypertensive therapy among diabetic hyperten- sive patients in Zewditu Memorial Hospital Addis Ababa. Ethiop Med J 54: 77-82.

7. Salvetti A, Ghiadoni L (2004) Guidelines for antihypertensive treatment: An update after the ALLHAT study. J Am Soc Nephrol. 15: 51-54.

8. Johnson ML, Singh H (2005) Patterns of antihypertensive therapy among patients with diabetes. J Gen Intern Med. 20: 842-846.

9. Black HR (2004) JNC 7 Treatment guidelines: Goals and recommendations. Cardiology Review 21: 37-45.

10. Dickstein K, Kjekshus J (2002) Effects of losartan and captopril on mortality and morbidity in high-risk patients after acute myocardial infarction: the OPTIMAAL randomised trial. Lancet. 360:752-760.

11. Aram V, Chobanian AV, Bakris GL, Black HR, George LWC et al. (2003) Joint National Committee on prevention, detection, evaluation, and treatment of high blood pressure. JAMA 289: 2560-2572.
12. Alavudeen SS, Alakhali KM, Ansari SMA, Khan NA (2015) Prescribing pattern of antihypertensive drugs in diabetic patients of Southern Province, Kingdom of Saudi Arabia. Ars Pharm 56: 109-114.

13. Dhanaraj E, Raval A, Yadav R, Bhansali A, Tiwari P (2012) Prescription pattern of antihypertensive agents in T2DM patients visiting tertiary care centre in North India. Int J Hypertens 120-129.

14. Jarari N, Rao N, Peela JR, Ellafi KA, Shakila S, et al. (2015) A review on prescribing patterns of antihypertensive drugs. Clin Hypertens 22: 112-116.

15. Wald DS, Law M, Morris JK Bestwick JP, Wald NJ (2009) Combination therapy versus monotherapy in reducing blood pressure: meta-analysis on 11,000 participants from 42 trials. Am J Med 122: 290-300.

16. Hansson L, Zanchetti A, Carruthers SG, Dahlöf B, Elmfeldt D, et al. (1998) Effects of intensive blood-pressure lowering and low-dose aspirin in patients with hypertension: principal results of the Hypertension Optimal Treatment (HOT) randomised trial. HOT Study Group. Lancet 351: 1755-1762.

17. Turnbull F, Neal B, Algert C, Chalmers J, Chapman N, et al. (2005) Effects of different blood pressure-lowering regimens on major cardiovascular events in individuals with and without diabetes mellitus: results of prospectively designed overviews of randomized trials. Arch Intern Med 165: 1410-1419.

18. James PA, Oparil S, Carter BL, Cushman C, Himmelfarb D, et al. (2014) Report from the panel members appointed to eight report of the Joint National Committee on prevention, detection, evaluation, and treatment of high blood pressure. JAMA 311: 507-520.

19. Giuseppe Mancia, Fagard R (2013) ESH / ESC Guidelines for the management of arterial hypertension. Eur Heart J 34:2159-2219.

20. Berlowitz DR, Ash AS, Hickey EC, Friediman RH, Glickman M, et al. (1998) Inadequate management of blood pressure in a hypertensive population. N Engl J Med 339: 1957-1963.

21. Brodalko B, Ruminska MCP (2007) An evaluation of the incidence and treatment of hypertension in diabetic patients based on a survey and a review of hospital documentation. Diabetol Clin Doc 7: 24-27.

22. Gerstein HC, Yusuf S, Mann JF, Hoogwerf B, Zinman B, et al. (2000) Effects of ramipril on cardiovascular and microvascular outcomes in people with diabetes mellitus: results of the HOPE study and MICROHOPE sub-study. Heart Outcomes Prevention Evaluation Study Investigators. Lancet 355: 253-259.

23. Lewis E, Hunsicker LG, Clarke WR, Berl T, Pohl MA, et al. (2001) Renoprotective effect of the Angiotensin-receptor antagonist Irbesartan in patients with nephropathy due to type 2 diabetes. N Eng J Med 345: 851-860. 